\title{
Object Lessons: Derek Mahon's Material Ekphrasis
}

Ekphrastic mode, with its emphasis on visual art, affords poets unique opportunities for exploring the limits of verbal art: for some writers, ekphrasis becomes almost a form of ars poetica by proxy. This is the case in many of Derek Mahon's ekphrases, as is well documented: Hugh Haughton proposes that for Mahon, paintings 'become...a site of metamorphosis and a figure for poetry'; '1 Terence Brown observes that 'Mahon's poems on paintings are striking occasions in his work when the claims of art itself are tested.'2 Mahon's self-reflexive use of ekphrasis has received substantial critical attention not only from Haughton and Brown but also from York, Kearney, Patke, Murphy, Sanders, Longley, Seree-Chaussinand, Cheeke, and others. ${ }^{3}$ What remains unexplored are the implications of Mahon's choice of ekphrastic source material. His ekphrases have been based on diverse works: paintings from a variety of eras (Munch, Van Gough, Pisanello, Uccello, de Hooch, Hopper, Wilks, Madden, Hodgkin, and Scott), sculpture, and various photographs. He frequently takes his inspiration not only from two-dimensional art forms but also from the three-dimensional objects and spaces they depict. It is not simply that Mahon responds to the objects visible in pictures - all ekphrases, except those based on very abstract artworks, could be seen to respond to the work's content as well as its form. Rather, Mahon responds to painted objects as though the objects themselves were functioning as the ekphrastic prompts. This phenomenon repays critical attention because the materiality of Mahon's ekphrastic writing shapes its metapoetic work in significant ways. In particular, questions surrounding abstraction and materiality emerge in a new light when the ekphrastic sources are material things, whether these be 'skinny beans and spoons'4 or 'candlesticks and jugs, bottles and bowls.'5

This discussion will begin with a brief outline of the theoretical association between ekphrasis and meta-artistic thought, including Mahon's own place in this history. I will focus on Mahon's later work, both because ekphrastic materiality expresses itself especially prominently here and because it has received less critical attention than earlier pieces (such as the muchexamined 'Courtyards in Delft'). I argue that turning attention to Mahon's material and architectural sources reveals new perspectives on the metaartistic function of his ekphrases. When Mahon uses the ekphrastic moment as a chance to meditate on his poetics, often his ideals emerge not as straightforward goals but as forcefields of productive contradiction: his use of objects as prompts is implicated both in his adumbration of ideals and in his questioning of them. Further, I will propose that Mahon's object-based ekphrases open new perspectives on ekphrasis as a theoretical category. Considering material objects disrupts, in particular, the framework of established assumptions surrounding the aesthetic merit of ekphrastic prompts. Mahon's invocation of crafted space (rooms and buildings) and household objects (many of 
which have a dimension of aesthetic value but are defined primarily by their instrumental use) complicates the definition of the ekphrastic source, raising complex questions about where the boundaries lie between ekphrastic form and cognate forms of description.

\section{Ekphrasis as ars poetica: materiality and abstraction}

Since the form's Homeric inception, theorists and practitioners of ekphrasis have treated it as a medium for self-reflexive contemplation: contemplation about the nature of one art form compared to another, about the arts as whole, and about art's relationship to social, ethical and political questions. By virtue of this history, comparative reflection on the contrasts and continuities between artforms has become part of the atmosphere of the form, regardless of how implicitly or explicitly these questions emerge in individual poems. ${ }^{6}$

The exploration of poetic ideals and their relationship to political ones plays an important role in Mahon's work, ekphrastic and otherwise. As numerous critics have shown, Mahon has consistently sought some degree of artistic independence, and this was especially visible when his historical circumstances made it difficult for him to avoid being positioned as a political voice. Haughton writes that 'Mahon's arrival on the literary scene coincided with the outbreak of 'The Troubles' and he would soon be identified as part of the 'Northern Irish Renaissance' that seemed their aesthetic double.'7 He notes that 'Mahon talked of being constantly asked, with Heaney and Longley, to give his 'views of the present crisis' in broadcasts and articles.'8 Mahon's much-cited comment about the poem as 'paradigm' is characteristic of his endeavour to maintain a civic voice that is participatory but indirect: "The poets themselves have taken no part in political events, but they have contributed to that possible life, or to the possibility of that possible life; for the act of writing is itself political in the fullest sense. A good poem is a paradigm of good politics - of people talking to each other with honest subtlety at a profound level.'9

As Brown has shown, Mahon's ekphrases have played a special role in his political and aesthetic negotiations. Brown proposes that ' $[\mathrm{i}] \mathrm{t}$ is in his poems on paintings that he confronts in a direct way an issue that troubles him throughout his work - that is whether the composed achievement of art may be an illusory misrepresentation of the real for all its beauty. ${ }^{10}$ He even describes Mahon's ekphrastic poem 'The Studio' as 'a kind of manifesto.'11

Ekphrasis is a fertile medium for these questions because it allows the poet to respond not only to the artwork itself but also to lived processes and behaviours of which the finished work is a trace (attentive observation, judicious witnessing, or conversely, disregard or misrepresentation). These processes can involve not only the actions of the artist but also the people depicted, and this detail is particularly significant in scenes of violence. For example, in 
Auden's 'Musée des Beaux-Arts',12 the poem is reacting both to the artist's own manner of responding to tragedy and to the manner of the people pictured. Given that one of Mahon's ongoing moral preoccupations involves writers' witnessing to injustice (as seen in the very wellknown 'A Disused Shed in Co. Wessex', for instance),13 ekphrasis becomes an especially charged form as it potentially comments on two levels of witness - that of the figures in the painting and that of the painting itself. Mahon's use of three-dimensional sources shapes these reflections in substantial ways. Many of the paintings to which Mahon's ekphrases respond involve either a three-dimensional object, or a two dimensional picture combined with the three-dimensional objects the picture represents, or even, as is the case with 'New Space', a room itself (rather than a painting of it) which is treated like an artwork. Poems based on artists' studios or pictures of studios are especially significant: they not only respond to the image of a room and the objects in it, but also raise the question of how this space provides the physical, spatial and interpersonal conditions for the creation of further artworks.

In 'Studio in Antibes', the poetic speaker takes on the voice of the artist to whom the poem is dedicated, De Staël, describing what it takes to 'get the picture out'.14 De Staël's 'I' merges with Mahon's own action in the poem, aided by the deictic 'here': 'here I renounce abstraction, / turning again / to the world of objects, to the stoical souls / of candlesticks and jugs, bottles and bowls.' 15 'New Space' responds not to an artwork representing a room, but to the room itself, described as though it were an artistic image. ${ }^{16}$ I include this poem among his ekphrases because of the explicit way in which the speaker confers the status of art object on the space: lines 9-10 declare that 'the place itself is a still life', and the preceding lines point out the room's visual details like a explicating gallery docent directing our gaze: 'just look / at how green light and shadow fall on the interior, jug, and bowl.'17 Mahon moves out from these details to consider his own aesthetic and ethical desiderata and how they are incarnated in the objects in the room, describing the objects as 'materials shaped by polished skills / in a time-honoured fashion, one that aims for a real thing well done / with real significance.' He stresses that 'it's all the one, the clay, the cloth, / art, music and organic growth nursing the venerable ideal / of spirit lodged within the real.' ${ }^{8}$ His decision to reflect on 'the real' in poems which use 'real' material objects as ekphrastic sources opens complex questions about the ability of verbal art to incarnate such materiality.

Hand in hand with 'the real' is Mahon's negotiation between private and public, and his use of domestic rather than public spaces becomes particularly significant. In 'The Studio' and 'New Space' alike, rooms for making arts and crafts are not commercial but home studios - he describes the Munch room which inspired 'The Studio' as 'the all-purpose bed-, work- and bedroom'. ${ }^{19}$ In 'New Space', the studio described is a sewing room in a converted space on the grounds of a private home. ${ }^{20}$ Domestic privacy here becomes a way to raise questions privacy 
itself, artistic and political. Mahon's inclusion of material objects and architectural spaces in his ekphrastic prompts creates another form of 'new space', opening an arena for the self-reflexive examination of ethical and poetic goals. Most importantly, as I will show in the next section, material ekphrases help Mahon to articulate the anxieties and ambiguities attending these ideals.

\section{III. 'Lines that say exactly what they mean'? Ambivalence in Mahon's material ekphrases}

Just as ekphrasis itself has long been associated with meta-poetic thought, so too has this form characteristically included anxieties and self-recrimination. Verbal attempts to represent visual art have often been accompanied by an acknowledgement that perfect mimesis is impossible. W.J.T. Mitchell has famously characterised three stances the writer can take towards the ekphrastic project - ekphrastic indifference, hope, and fear. Ekphrastic indifference 'grows out of a commonplace perception that ekphrasis is impossible. ... a verbal representation cannot represent - that is, make present, its object in the same way a visual representation can.'21 'Ekphrastic hope' refers to an appreciation of those ways in which this divide might be bridged, 'in imagination or metaphor'. In turn, 'ekphrastic fear' is the suspicion that in finding ways to approximate visual representation in verbal modes, the distinctiveness of verbal representation might disappear from view. ${ }^{22}$ For Mitchell, 'the interplay of these three 'moments' of ekphrastic fascination - fear, hope and indifference - produce a pervasive sense of ambivalence...'. ${ }^{23}$ As James Heffernan and others have observed, postmodern writers of ekphrasis introduce a further form of ambivalence, asking whether replication is even desirable: 'postmodern ekphrasis undermines the concept of verisimilitude itself.'24 A dynamic of productive resignation is the result: a sense that the ekphrastic attempt will only ever be an attempt, but also that this very shortfall is a source of value. In this spirit of resignation, such a shortfall resonates closely with Mahon's poetics of productive failure and of the luminously rueful, visible in his ekphrases and beyond.

In the context of the ambivalence written into ekphrastic form, Mahon's engagement with material objects, and the specific form of ambivalence they create, becomes especially relevant. Many of his ekphrases about three-dimensional objects express a desire to approach concreteness, but at the same time, they show the impossibility - and sometimes even the undesirability - of this. 'New Space' is especially relevant in that it at once explores ideals and raises anxieties about them, and material objects are central to both the ideals and their destabilising. 25 'Courtyards in Delft' is an important precursor. Just as the earlier poem is as uneasy as it is appreciative of the frugal cleanliness characterising both de Hooch's painting and 
the lives depicted in it, so too does this poem ultimately reveal ambivalence, rather than unalloyed appreciation, of the neat simplicities it explores. Central to the ideals engaged in the poem is 'the venerable idea / of spirit lodged within the real': the embodiment of ideas in material solidity. 26 The final stanza emphasises how the poem's aesthetic principles turn on a renunciation of abstraction: 'The weight of a bone-handled knife / signifies more in human life / than our aesthetics ever can; / form follows function. ...'27 This declaration is a renunciation of rules and at the same time a rule in itself, written in the diction of universal prescription and even cliché. By virtue of participating in the modes of both ars poetica and ekphrasis - modes associated with large abstract questions - the poem already implicitly deals in the abstraction it rejects. This engagement becomes explicit as the poem moves from the description of particular art objects towards general statements about art itself: the lines render up real things - jug and bowl, planted row, knife - but also consider 'the real' as an intellectual category.

The poem's destabilising of its own materiality principle is furthered by its invocation of Tolstoy. The poem stresses his affinity for the solid and simple, extending to literature:

Tolstoy, who later disapproved of opera, plays and novels, loved doorknobs, utensils, toys and song, the homespun that the peasants wore everything simple, strong and clean, art that was modest, not a chore; and rhyming verses, not too long, that say exactly what they mean. ${ }^{28}$

Mahon's own lines here are 'rhyming verses, not too long': the stanzas have a neatlyturned, if not quite regular, rhyme scheme which links lines with ringing closure. However, they do not, quite, 'say exactly what they mean.' The similarities to 'Courtyards in Delft' contribute to this - any poem which uses the words 'modest' and 'clean' to describe a way of being and making art cannot but introduce echoes of the earlier poem's ironies, particularly those of its first stanza:

Oblique light on the trite, on brick and tile Immaculate masonry, and everywhere that Water tap, that broom and wooden pail To keep it so. House-proud, the wives 
Of artisans pursue their thrifty lives

Among scrubbed yards, modest but adequate.

Foliage is sparse, and clings. No breeze

Ruffles the trim composure of those trees. ${ }^{29}$

[Insert Figure 1 here] It is a critical commonplace that while 'Courtyards in Delft' describes the artistic and personal values of a modest tidiness it also, to some degree at least, calls them into question: 'we miss the dirty dog, the fiery gin.'30 Brown captures this dual allegiance when he writes that 'the poet both censures a reality of limited possibilities - implicit provincial rectitude, underlying colonialism - and is moved by the values immanent in the scene portrayed in the canvas. '31 When words like 'modest' and 'clean' and 'swept and scrubbed' reemerge in 'New Space', they come shadowed with a scepticism they inherit from the older poem. Mahon's use of real objects as ekphrastic prompts in 'New Space' thus emerges as essential to the poem's adumbration and questioning of its central ideals.

In a different context, 'Cushenden in Winter' made direct reference to 'aesthetics' in order to set abstract rules in an ironised, half-committed light: 'Cushenden in Winter' remembers Maurice Wilks' own aversion to formal rules: 'Wilks never bothered with 'the picture plane', / with 'colour values' and the fancy words - / as for aesthetics, that was for the birds.' 32 While there is no undercutting of Wilks' own belief here, the description of the rules is nonetheless complicated by virtue of the fact that it is made in an ekphrasis, a form which turns on the difference between visual art and 'fancy words'. In 'Shapes and Shadows', likewise, the attention paid to objects is key to its presentation of complex ideals. [Insert Figure 2 here]. The poem describes the artist William Scott's process as one which transforms concrete objects through abstraction:

Too much the known structures

those simple manufactures, communion of frying pans, skinny beans and spoons, colander and fish slice in a polished interior space.

But tension of hand and heart abstracted the growing art to a dissonant design and a rich dream of paint, ${ }^{33}$ 
These lines describe a process of transmuting things in their everyday state into something else, though the exact implications of diction in the first phrase are ambiguous. In one interpretation, the first two lines can be read as though 'known' functions as an adjective modifying 'structures' and the whole line describes 'those simple manufactures.' This interpretation would assume the elision of 'are' and an archaic inversion of subject and predicate, which places the subject of the description last ('those simple manufactures' [are] 'too much the known structures'). Alternatively, the lines can be read as though 'the known' is the subject of the verb 'structures' and 'those simple manufactures' form the verb's object. In both cases, though, ideas of familiarity and simplicity are presented as a problem - that which involves an excess, 'too much' - and they are opposed against a process of abstraction through the 'but' which begins the next stanza. Conversely, the poem's end, through an emphasis on surfaces, valorises objects in their unabstracted as well as their abstracted form. The final two stanzas present a second instance in which a process of renewal and transformation is described ('start again on the fresh / first morning of the world'), but here it is not abstraction which is transformative but a focus on the surface of the materials, the 'nitty-gritty':

with snow, ash, whitewash, limestone, mother-of-pearl,

bleach, paper, soap, foam and cold kitchen cream, to find in the nitty-gritty of surfaces and utensils the shadow of a presence, a long-sought community. ${ }^{34}$

In this ekphrasis-as-ars-poetica, as in 'New Space', the poem's treatment of real objects is central to its negotiation of ideas about abstraction and materiality. Where 'New Space' makes declarative statements about abstraction and then complicates them through its own practice, renouncing universal dicta as it utters them, here the ambiguity emerges through a commingling of abstract and concrete. In the poem's ending list, the materials which evoke 'the shadow of a presence, a long-sought community' include items which can act as artists' materials but which also have an everyday use. They are associated with abstraction in that they can create colour and surface ('whitewash' and 'limestone'), but they are also concrete items with a specific domestic function. As the list grows, the identity of the objects combines 
the designation of colour with household utility even more closely: 'bleach, paper, soap, foam / and cold kitchen cream.'

Mahon's own artistic process in the poem's composition reflects this awareness of the universal in the specific. The words themselves, like the substances they denote, can designate at once an abstract form - the colour of whitewash, of mother-of-pearl, paper - and the specific household substance. 'Cream' is at once edible and a form of off-white. By showing how in a painting a colour is both abstract and referential, the poem meditates on the layering of abstraction and denotation in our vocabulary for colour. In presenting two moments of artistic transformation and renewal, and focusing one on abstraction and the other on material surfaces in which the abstract and the concrete come commingled, the poem thus complicates the valorising picture of abstraction it initially presents. These three examples help to show how exploring Mahon's ekphrases from the perspective of their engagement with three-dimensional objects can help shed light on the ambivalence which attends their ideals. Attention paid to this materiality not only holds implications for the study of Mahon's own work: it also opens new critical questions about the form itself.

\section{Materiality and the limits of ekphrastic form}

Mahon's use of objects as ekphrastic source material generates, in particular, useful lines of questioning around the distinction between ekphrasis and more general categories of description. As W.J.T. Mitchell has noted, this boundary has long proved difficult to establish, ${ }^{35}$ and as a consequence, definitions of ekphrasis must necessarily engage with questions about value, such as: is the use of ekphrastic form predicated on the assumption that the source object already has the status of an artwork, or can the status of art object be conferred by the writing of an ekphrasis? Is the category of 'art' itself being used to indicate a type of endeavour and product, or a level of merit? Could ekphrases, theoretically, be written about bad art? Can good ekphrases be written about bad art? Does including (as Mahon does in 'New Space', for instance) a household knife in an ekphrasis confer artistic value on an object defined more by its utility than its aesthetic properties, or does it do the more complex work of acknowledging that the object might have a prior artistic value; a value which predates the present frame?

Further, Mahon's emphasis on material objects speaks to a foundational ekphrastic problem: if one of the potential functions of ekphrasis is to aim for a verbal equivalent of visual material, what does it mean for words to incarnate the physical presence of visual art? Would this involve a Hopkins or Heaneyesque attention to the materiality of sounds as felt products of the body and mouth? Or a concrete poet's attention to spatial arrangement as a more visually mimetic form of materiality? Some of Mahon's ekphrases do function as concrete poems, such 
as 'The Hunt by Night' which, as Haughton notes, has a 'systematically rhymed concertina form. '36 Parsing Sigurd Burckhardt, Murray Krieger has discussed poetry's striving towards the material state of other artforms: 'the poem must convert the transparency of its visual medium into the physical solidity of the medium of the spatial arts.' 37 When the spatial art concerned is itself three- rather than two- dimensional, this challenge becomes especially acute.

In Mahon's case the challenge stands out even more by virtue of the contrast with his many ekphrases about photography. Matching 'the physical solidity' of the 'spatial arts' is a very different proposition when the artform concerned is as minimally material as a photograph. Matching a photograph might involve, accordingly, an attention to replicating the mode of viewing or representing, rather than the finished product. Such replication is analogous to that defining the post-modern 'painterly' ekphrasis as theorised by Michael Davidson: 'The contemporary painterly poem shares many of the characteristics of its predecessors of the seventeenth or eighteenth-centuries, but with a stronger emphasis on its ability to embody the painting's formal strategies and with less emphasis on its mimetic potential.' 38 Indeed, Hugh Haughton has described some of Mahon's work as 'developing its own photographic idiom',39 presenting, for example, 'painterly or photogenic impressions of sea and clouds. ${ }^{40}$ Cultivating a photographic idiom in a painting might involve the poet making judgements less about the product and more about the process and the values informing it, in this case, perhaps a sense of commitment to documentary accuracy, witnessing, authenticity or participation. The contrast between the materiality and immateriality of Mahon's various ekphrastic sources thus contributes to the challenge of defining what imitation means in poetic responses to visual art.

Mahon's materially-based works also offer new angles on the representational status of source-objects, raising questions about how the nature of an ekphrasis changes according to whether the source object is itself representational or abstract. Representational sources generate difficulties in distinguishing between the visual material itself and its conceptual, narrative and iconographic history. ${ }^{41}$ As Stephen Cheeke has pointed out, many visual artworks which function as ekphrastic prompts are themselves based on writing. Auden's 'Musée des Beaux Arts', for instance, is based on Breughel's painting titled 'Landscape with the Fall of Icarus', but the mythological story of this painting has previously been expressed in many other forms, both visual and verbal. ${ }^{42}$ Therefore, what Auden is responding to is at once the generalised idea of the Icarus myth and the specific incarnation of this myth in Breughel's painting.

When the ekphrastic prompt is a three-dimensional object, its representational dimension has two levels - that of the images depicted by the object and that of the object itself. ${ }^{43}$ In the case, for instance, of Keats' 'Ode on a Grecian Urn', the ekphrasis is responding to a representational image - the scene depicted on the urn's surface - but also to the three- 
dimensional shape and presence of the urn itself, which, if it can be considered representational, represents in a very different way. This mode of representation necessarily rests on the ontological question of whether an object simply manifests a category, or whether it also represents that category: Keats' object is an urn - does it also represent the idea of an urn, and in what sense? How much, furthermore, does the object's representative power inhere in the object prior to being described and how much does it depend on what the ekphrastic poem says about it? Keats' poem, for instance, calls attention to the cultural resonances of the urn's physical presence in calling it an 'attic shape', but this is a much more diffuse kind of representation than the figuring of maiden and lover. The opposite scenario arises in the ekphrases about photographs discussed above, in that these may (like paintings) depict concrete objects, but through a medium which, in its lack of textural materiality, is the opposite of an urn or a vase, so here the dance between materiality and immateriality is reconfigured inversely. These are large questions in the history of interartistic aesthetics, but outlining them here helps to show the scale of critical complications surrounding the problem of materiality in ekphrasis: a problem to which Mahon's work speaks in complex ways. To attend to the presence of material objects in Mahon's ekphrases, then, is to gain new perspectives not only on his own use of the form, but also on ekphrastic mode itself and its foundational interpretative difficulties.

\footnotetext{
${ }^{1}$ Hugh Haughton, The Poetry of Derek Mahon (Oxford: Oxford University Press, 2007), 181.

2 Terence Brown, 'Derek Mahon: The Poet and Painting,' Irish University Review 24, no. 1 (1994): 46.

${ }^{3}$ See Richard York, 'Derek Mahon and the Visual Arts,' in The Poetry of Derek Mahon, ed. Elmer KennedyAndrews (Gerrard's Cross: Colin Smythe, 2002), 131-44; Rajeev S. Patke, 'Painting into Poetry: the Case of Derek Mahon,' Word \& Image: A Journal of Verbal/Visual Enquiry 22, no. 2 (2006): 118-127; Shane Murphy, 'The Eye That Scanned It': The Picture Poems of Heaney, Muldoon, and McGuckian,' New Hibernia Review 4, no. 4 (2000): 85-114; Leonard Sanders, 'The Politics of Art: Derek Mahon's 'Girls on the Bridge' and Paul Muldoon's 'Paul Klee: They're Biting', The Harp 10 (1995): 24-29; Edna Longley, 'No More Poems about Paintings?,' in The Living Stream: Literature and Revisionism in Ireland (Newcastle upon Tyne: Bloodaxe Books, 1994), 227-51; Christelle Seree-Chaussinand, "Bring out artists; take music, of the calm light of Dutch interior art...': Derek Mahon's Pictorial Poems; Interfaces 29 (2009-10): 217230; Stephen Cheeke, Writing for Art (Manchester: Manchester University Press, 2008).

4 Mahon, 'Shapes and Shadows,' New Collected Poems (Loughcrew: Gallery Press 2011), 240.
} 
${ }^{5}$ Mahon, 'Studio in Antibes,' New Collected, 301.

${ }^{6}$ For a discussion of this history, see: Cheeke, Writing for Art, 11-36; James Heffernan, Museum of Words: The Poetics of Ekphrasis from Homer to Ashbery (Chicago: University of Chicago Press), 9-45; Murray Krieger, 'Ekphrasis: The Illusion of the Natural Sign', The Play and Place of Criticism (Baltimore: Johns Hopkins University Press, 1967), 3-26.

${ }^{7}$ Haughton, Mahon, 52.

${ }^{8}$ Haughton, Mahon, 83.

${ }_{9}^{9}$ Mahon, 'Poetry in Northern Ireland,' Twentieth Century Studies 4 (1970): 93.

${ }^{10}$ Brown, 'Poet and Painting,' 44.

${ }^{11}$ Brown, 'Poet and Painting,' 48.

12 W.H. Auden, 'Musée des Beaux-Arts,' Collected Poems, ed. Edward Mendelson (London: Faber, 1991 [1976]), 179.

${ }^{13}$ Mahon, 'A Disused Shed in Co. Wessex', New Collected, 81-2.

${ }^{14}$ Mahon, 'Antibes,' 301.

15 Mahon, 'Antibes,' 301.

${ }^{16}$ Mahon, 'The Studio,' New Collected, 37.

17 Mahon, 'Studio,' 37.

18 Mahon, 'Studio,' 37.

${ }^{19}$ Mahon, 'Studio' 37.

${ }^{20}$ I am grateful to Peter Fallon for pointing out this detail in discussions at the Third British and Irish Contemporary Poetry Conference, University of Manchester, September 15-17, 2013.

${ }^{21}$ W.J.T. Mitchell, Picture Theory: Essays on Verbal and Visual Representation (Chicago: University of Chicago Press), 152.

${ }^{22}$ Mitchell, Picture Theory, 154.

${ }^{23}$ Mitchell, Picture Theory, 156.

${ }^{24}$ Heffernan, Museum, 4.

25 Mahon, 'New Space,' New Collected, 336-7.

${ }^{26}$ Mahon, 'New Space,' 336.

${ }^{27}$ Mahon, 'New Space,' 337. 
${ }^{28}$ Mahon, 'New Space,' 336.

${ }^{29}$ Mahon, 'Courtyards,' 96.

30 Mahon, 'Courtyards,' 96.

${ }^{31}$ Brown, 'Poet and Painting,' 48.

32 Mahon, 'Cushenden in Winter,' New Collected, 302.

33 Mahon, 'Shapes,' 240.

${ }^{34}$ Mahon, 'Shapes,' 241.

35 Mitchell, Picture Theory, 159.

${ }^{36}$ Haughton, Mahon, 156.

${ }^{37}$ Krieger, Illusion, 266.

${ }^{38}$ Michael Davidson, 'Ekphrasis and the Postmodern Painter Poem,' The Journal of Aesthetics and Art Criticism 42, No. 1 (1983), 71-2.

${ }^{39}$ Haughton, Mahon, 339.

${ }^{40}$ Haughton, Mahon, 337.

${ }^{41}$ Willard Spiegelman, How Poets See the World (New York: Oxford University Press, 2005), 135.

${ }^{42}$ Cheeke, Writing, 106.

${ }^{43}$ Krieger's discussion of ekphrastic urns and the representative functions of the object's shape is relevant here: see 'Ekphrasis', p. 8-16. 


\section{Figures}

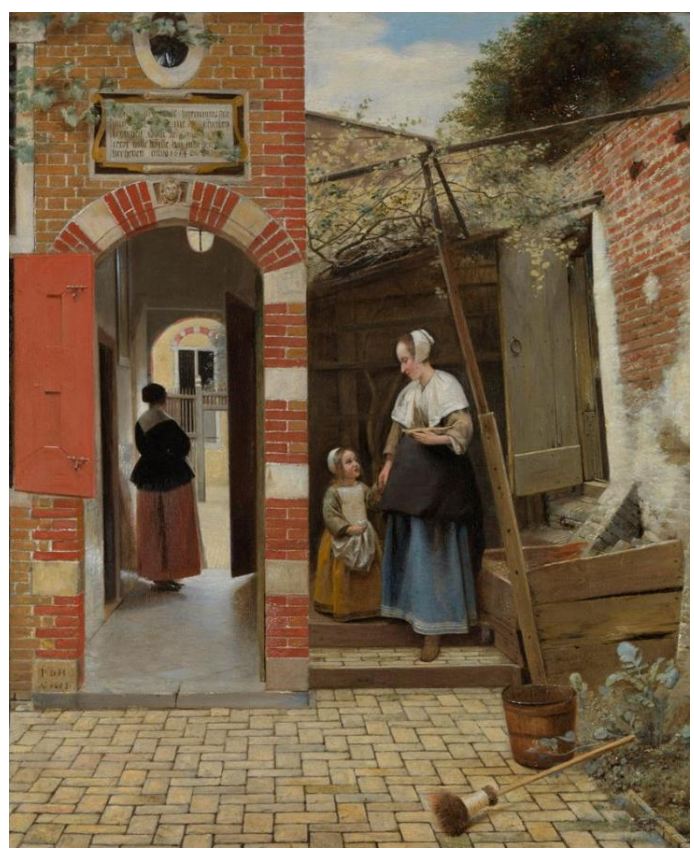

Fig. 1. Pieter de Hooch, The Courtyard of a House in Delft, 1658. Oil on canvas, 73.5 x 60 cm. National Gallery, London. Reproduced from ArtStor, http://www.artstor.org (accessed 20 May 2014).

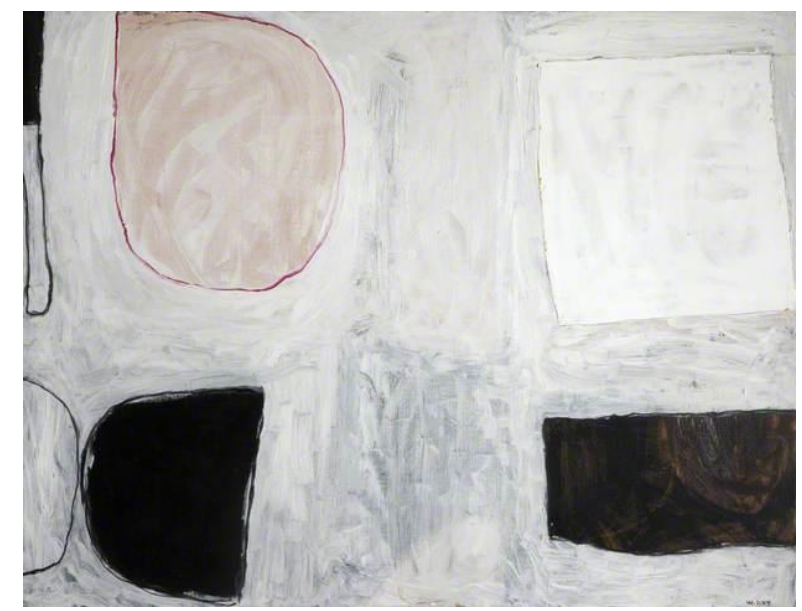

Fig. 2. William Scott, Shapes and Shadows, Oil on canvas, $86 \times 112 \mathrm{~cm}$. (C) Estate of William Scott, 2014. Ulster Museum, Belfast. Reproduced from $B B C$, http://www.bbc.co.uk (accessed 20 May 2014). 


\section{Abstract}

Derek Mahon, like many writers of ekphrastic poetry, uses the interartistic encounter as an opportunity to meditate on his own aesthetic practice. While the self-reflexive dimensions of Mahon's ekphrases have received considerable critical attention, the implications of his choices of source material are underexamined. Many of Mahon's ekphrases respond not simply to paintings, but to works depicting three-dimensional objects and architectural spaces: indeed, he sometimes treats rooms and things as though they were the art objects in question. This is the case in a variety of poems, from 'Courtyards in Delft' and 'The Studio', to later ekphrases like 'Shapes and Shadows', 'Studio in Antibes', and 'New Space'. As these titles suggest, many of the objects and spaces he chooses are those used in the production of further artworks - some of his best known material ekphrases are responses to artists' rooms. This predilection repays critical attention, as the materiality of Mahon's ekphrastic writing shapes its metapoetic work in significant ways. Many of Mahon's aesthetic reflections concern abstraction, materiality, craft and making, and these concerns take on additional complexity when the ekphrastic sources themselves involve physical things. Most importantly, Mahon's material ekphrases shed light on some of the ambivalence and ambiguity attending his aesthetic ideals.

\section{Keywords}

Mahon, ekphrasis, materiality, aesthetics, poetics. 